\title{
Outcome of patients treated with N-Butyl-2-cyanoacrylate in gastric variceal bleeding.
}

1. MBBS, FCPS

Associate Professor Radiology

Sindh Institute of Urology and

Transplantation,

Karachi.

2. MBBS, FCPS

Assistant Professor

Gastroenterology

Liaquat University of Medical and

Health Sciences, Jamshoro.

3. MBBS, FCPS

Consultant Gastroenterologist

Civil Hospital Larkana.

4. MBBS, FCPS

Assistant Professor Radiology

Liaquat University of Medical and

Health Sciences, Jamshoro.

Correspondence Address:

Dr. Riaz Hussain Awan

Department of Gastroenterology

Liaquat University of Medical and

Health Sciences, Jamshoro.

dr.awan.riaz@gmail.com

Article received on:

29/05/2021

Accepted for publication:

$21 / 08 / 2021$

\section{INTRODUCTION}

Though bleeding from esophageal varices is less frequent but in terms of severity it is leading then the bleeding from gastric varices so definitely it has more chances of rebleeding and more chances of mortality and it is of great medical challenge to overcome this. ${ }^{1}$

Themostcommonsitesforvaricesingastrointestinal tract are esophagus and stomach albeit they may occur along different sites of gastrointestinal tract. To treat varices various therapeutic measures are available which can overcome this problem like transjugular intrahepatic portosystemic shunt (TIPS), endoscopic obliterative therapy with cyanoacrylate and balloon-occluded retrograde transvenous obliteration (B-RTO). About $50 \%$ to $60 \%$ of cirrhotic patients may develop varices from gastroesophageal region while gastric varices accounts for $10 \%$ to $15 \%$ which can develop bleeding somewhere in life. ${ }^{2}$ In patients who are diagnosed as cases of gastric varices used to have portal hypertension and can complicate gastric varices severely. ${ }^{3}$

GVs are classified as primary when they occur primarily in continuation with EVs whereas secondary GVs occur after obliteration of EVs. ${ }^{3}$ Varices of the gastric fundus (fundal varices FV) are initiated by the dilation of short or posterior gastric veins and are frequently associated with a large gastro renal shunt. ${ }^{4}$ Gastro esophageal varices (GOV) were further sub classified as GOV1 (Esophageal varices extending down to cardia or lesser curvature) and GOV2 (Esophageal varices extending to gastric fundus). ${ }^{5}$

About $20 \%$ of all variceal bleeds are due to GVs. Literature suggests that GVs are found in approximately $22 \%$ of cirrhotic patients with 
portal hypertension. ${ }^{6,7}$ About $15-25 \%$ of GVs bleed during their lifetime. ${ }^{4}$

The treatment of hemorrhagic FV by endoscopic procedures sometimes fails to cease the bleeding, and surgical modalities are thus often required for hemostasis ${ }^{3}$, As a result, the mortality rate is high in patients with hemorrhagic $\mathrm{FV}^{3}$

There is significant morbidity and mortality are associated with the bleeding gastric varices and mortality rate ranges from $25 \%$ to $55 \% .{ }^{4}$ Although several recent developments in the agents and the techniques have improved the outcome of GVs bleeding No consensus has been reached on the optimum treatment. ${ }^{1}$ Nowadays gastric varices have been treated with new therapeutic options like interventional radiology and endoscopic measures. ${ }^{2}$ As compared to endoscopic treatment the therapeutic measures by cyanoacrylate has been shown to have excellent results not only in terms of providing hemostasis but also favors less chances of rebleeding. ${ }^{5,9}$

Comparisons have been made between the effectiveness of cyanoacrylate and propranolol for managing bleeding from gastric varices but so far there is very limited data but some randomized controlled trials have shown that tissue adhesives as superior in managing bleeding gastric varices albeit the general management for bleeding from esophageal and gastric varices is same. ${ }^{7}$

Many countries like Italy, Germany, Pakistan, India, and Canada are using cyanoacrylate for treating bleeding gastric varices as the treatment of choice though still it has not got universal acceptance. We have 5 years of experience in using cyanoacrylate in treating gastric variceal bleeding and sharing our experience in their outcomes.

\section{MATERIAL \& METHODS}

A Retrospective study was conducted at Liaquat University of Medical and Health Sciences, Jamshoro from December 2019 to March 2020 by consecutive sampling as per medical records and inclusion criteria in data collection procedure. Endoscopy reports and medical records were noted after approval from ethical review committee NO. LUMHS/REC/-963 to sort out patients with variceal bleeding along with any comorbid, gender, age and clinical outcomes in achieving hemostasis and possible procedure related complications were recorded.

$\mathrm{N}$-butyl-2-cyanoacrylate was injected to stop bleeding from gastric varices in 31 patients under endoscopic guidance. Those patients having chronic disease of liver along with complaints of bleeding per rectum and hematemesis were included in this study while those with portal hypertension due to non-cirrhotic causes and having hepatic encephalopathy were excluded from this study.

Seewald etal ${ }^{26}$ recommended the use of Histoacryl injection for treatment of varices which was made by mixing it with lipiodol solution in a quantity of $0.5 \mathrm{ml}$ of Histoacryl and $0.8 \mathrm{ml}$ of lipiodol. Mixing will solidify the solution and prevents it from adherence to endoscope and catheter as well as make it easier to inject via endoscope. Initially priming of sclerotherapy needle of 21-22 gauges was done with 0.8 to $1.2 \mathrm{ml}$ of Lipiodol followed by targeted puncturing and injection of solution into the varix. Figure-1 is showing multiple gastric varices mainly in fundal region and bleeding can be seen from varices, after Histoacryl injection the bleeding was completely stopped and aim achieved.

Data was collected from medical records of patients who had presented with history of upper gastrointestinal bleeding from gastric varices, attending Gastroenterology department admitted through emergency in our hospital. Initially endoscopic reports of all upper Gl bleed patients were sorted out for the source of bleeding. Later medical records will be taken in view and will be followed up to see the outcome after procedure. To control the confounder's evaluation of all the records will be done by a researcher himself. All the relevant information will be entered on the annexed proforma. After taking informed consent data was collected from patients admitted through Emergency Department and Out Patient Clinics who presents with history of 
hematemesis, melena, undergoing gastroscopy and fulfilling inclusion and exclusion criteria. Patient's clinical history, comorbid like DM, HTN, IHD (confirmed on documented record of history and on treatment) and examination was done by principal investigator as per operational definitions. Gastroscopy was performed after taking consent and explaining the benefits and complications of the procedure. Gastroscopy was performed by experienced gastroenterologist. Initially Dormicum injection was given and on gastroscopy when dark brown colored clotted blood was noted that labelled as bleeding from Gastric varices. All demography, clinical history was recorded by a principal investigator on a predesigned Performa. Effect modifiers and biasness was controlled by strictly following the inclusion and exclusion criteria

Statistical package of social science (SPSS.18) for windows was used to analyze data. Mean \pm Standard deviation was calculated for quantitative variables like age and duration of symptoms. Frequencies and percentages were calculated for qualitative variables like gender, comorbid like DM, HTN, IHD and GVs bleeding. Stratification was done with regard to age, gender, duration of symptoms. DM, to see the effect of these effect modifiers on outcome variable like hemostasis, mortality, hospital stay and need of blood transfusion) buy using Chi-square test and considering $P$ value $\leq 0.05$ significant.

\section{RESULTS}

On emergency basis after administration of octreotide via intravenous route, all 31 patients were treated with N-butyl-2-cyanoacrylate injection which was administrated endoscopically to manage gastric variceal bleeding. Most of the patients were males 18 (58.1) with average age of $55.23 \pm 8.778$ and range of (38-72) years old. Cirrhosis due to Hepatitis $C$ and $B$ was the cause in all cases for gastric variceal bleeding and among them $12.9 \%$ of patients were categorized as class A liver status while class B constitutes $64.5 \%$ and class $\mathrm{C}$ includes $22.6 \%$ as per Child-Pugh classification (Table-I). In 27 patients bleeding from varices was stopped with just a single injection of cyanoacrylate while one among them required repeat injection of glue within 48 hours of initial procedure due to continuous bleeding. Among these 4 patients did not achieve hemostasis and was referred for TIPS procedure. Second clinical outcome, Overall mortality rate was 3 out of $31(9.7 \%)$, it was attributed to rebleeding. Third clinical outcome we checked blood transfusion, Almost All patients with bleeding gastric varices required blood transfusion prior to endoscopy or during hospital admission.54.8\% of patients required less than 3 pint of Blood, 32.3\% of patient had 4 to six of pint of blood transfused \& $12.9 \%$ of patients were transfused greater than 7 pint of blood. A total of 3 patients out of $31(9.7 \%)$ died during hospital stay, deaths were related to the gastric varices re-bleeding and advanced cirrhosis. Average duration of hospital stay was 5 to 8 days in 22 cases $(71.0 \%)$. There was $29 \%$ of patient who were admitted for four days and discharged without developing any complications.

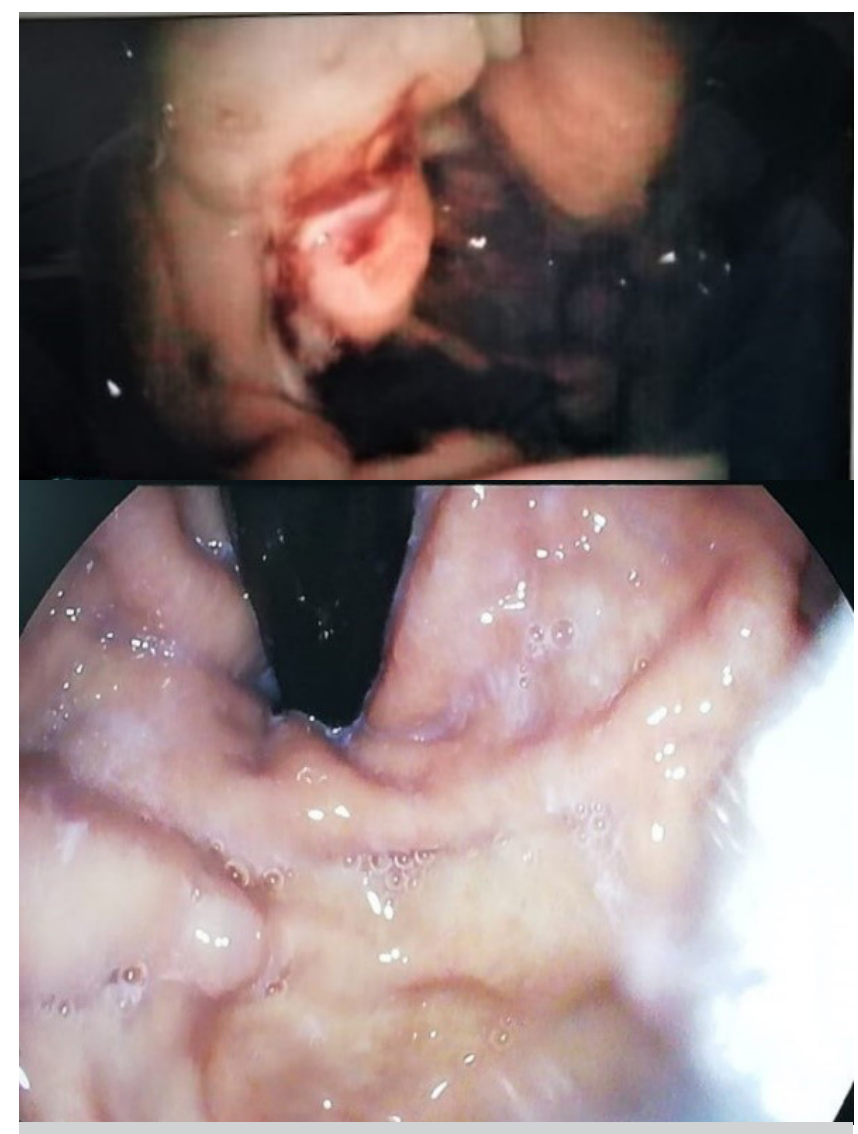

Figure-1. Pre and Post histoacryl injection in gastric varices. 


\begin{tabular}{|c|c|}
\hline Variable & n (\%) \\
\hline Age, years (range) $55.23 \pm 8.778$ ( $38-72)$ & 18 (58.1). \\
\hline Male & 13 (41.9) \\
\hline Female & \\
\hline Clinical presentations & $24(77.4)$ \\
\hline Hematemesis & $07(22.85)$ \\
\hline Melena & \\
\hline Etiology of cirrhosis & 05(16.12) \\
\hline Chronic hepatitis B & 26(83.87) \\
\hline Chronic hepatitis C & \\
\hline Comorbidities & $10(30)$ \\
\hline Diabetes mellitus & $(12.90)$ \\
\hline Renal failure 04 & \\
\hline Liver status by Child-Pugh classification & $04(12.90)$ \\
\hline Class A & $(64.51)$ \\
\hline Class B 20 Class C & $07(22.58)$ \\
\hline
\end{tabular}

\section{DISCUSSION}

About $10 \%$ to $20 \%$ of cases of variceal bleeding occurs due to portal hypertension while other causes like inflammation and neoplastic process of pancreas leads to extrahepatic obstruction of portal vein also lead to variceal bleeding indirectly. ${ }^{8}$ and our study has shown obvious safety and outcomes in using N-butyl-2-cyanoacrylate (Histoacryl) in treating variceal bleeding from stomach.

There is not much availability of therapeutic options for treating gastric variceal bleeding compared to other modalities available for treating bleeding EV. However, endoscopic N-butyl-2cyanoacrylate (NBCA) injection of GV remains the recommended option according to guidelines. ${ }^{9}$ Soehendra et al., first reported GV histoacry/ ${ }^{\circledR}$ injection in $1986 .{ }^{10} \mathrm{~A}$ study by Lo et al concluded that endoscopic obliteration using band ligation is less effective and more difficult than cyanoacrylate injection in the management of bleeding GV. ${ }^{11}$ Best alternative to endoscopic treatment are Transjugular intrahepatic portosystemic shunt (TIPS) and Balloon-occluded Retrograde Transvenous Obliteration (BRTO). There is usual requirement of a proper team for patients who undergo BRTO as this procedure has chances of complications.

All patient Underwent treatment for secondary prevention of rebleeding. There are some guidelines recommend the use of non-selective
B-blockers too stop bleeding from gastric varices. Contrary, GV Histoacryl injection is considered the standard of care in some centers for primary and secondary prevention of GV bleeding. ${ }^{12}$ Of 31 cases, $18(58.1 \%)$ were male and 59(43.7\%) were female, showing male gender predominance and this predominance supported in Mosli $\mathrm{MH}$ et al. ${ }^{13}$ they reported $79.3 \%$ of males. Rania Hadayat et al reported $62.7 \%$ males $^{14}$ Khalid Hameed et al in their study reported $55.5 \%$ of male gender and male to female of $1.25:{ }^{15}$ Age ranges from 38 to 72 years with an average age of $55.23 \pm 8.778$ years in our study. More or less similar age findings were reported by Shaikh Samiullah et al who included $71.7 \%$ of males with average age of patients was $45 \pm 13$ years. ${ }^{16}$ and. Mosli $\mathrm{MH}$ et al reported mean age of 60.8 years. ${ }^{13}$ Abbas Khanet $\mathrm{al}^{17}$ reported mean patient age was 47.26 \pm 12.20 . N-butyl-2-cyanoacrylate in gastric variceal bleeding management is effective and safe, we checked four outcomes in our study, Hemostasis, mortality, Hospital stay and need of Blood transfusion.

Hemostasis was achieved in 27 patients (87\%). Only four patients had persistent bleeding and one patient requiring TIPS insertion, there were no case of rebreeding from GV in our study noted during hospital stay. Important predictors of gastric variceal bleeding include presence of GV, hepatic vein pressure gradient (HVPG) greater than $16 \mathrm{mmHg}$, associated diagnosis of HCC and a MELD score greater than $15^{18}$, these poor prognostic factors had high chances in causing significant mortality. ${ }^{18}$ High rate of hemostasis approximately $95 \%$ observed in AlAli $\mathrm{J}$ et al study on Endoscopic management of gastric variceal bleeding with cyanoacrylate glue injection, rebleeding were seen in $8.1 \%$ albeit in this splenectomy was done in one patient while Tips insertion was required and carried out in other. ${ }^{19} \mathrm{~A}$ meta-analysis suggested that endoscopic cyanoacrylate injection and EVL are equally effective for initial hemostasis of bleeding gastric varices, while cyanoacrylate may be more efficient for preventing rebleeding. ${ }^{20}$ The overall post procedure mortality is 3 out of $31(9.7 \%)$ and it is similar to that reported in Al-Ali $\mathrm{J}$ et al. ${ }^{19}$ This is supported by a recent meta-analysis that 
showed that EVL is superior to sclerotherapy in this setting, with EVL being associated with a significant improvement in bleeding control when compared to sclerotherapy $(\mathrm{RR}=1.08 ; 95 \% \mathrm{Cl}$, 1.02-1.15) ${ }^{21}$ Oho $\mathrm{K}$ et al a nonrandomized study suggested $\mathrm{N}$ butyl cyanoacrylate is superior to ethanolamine oleate in achieving hemostasis, and have survival advantage and $\mathrm{Oh}$ et al. elaborated their experience in their study of 21 patients, the mean volume to obliterate in gastric varices ranged from 0.25 to $0.5 \mathrm{ml}$ with no complication. ${ }^{22}$

$\mathrm{N}$-butyl, 2-cyanoacrylate had initially controversial safety due to immediate and late complications, as some complications were fatal. ${ }^{23}$ These data suggest that endoscopic therapy with tissue glue (NBCA) achieves initial hemostasis of bleeding gastric varices in $80 \%$ to $90 \%$, is more effective than band ligation or sclerotherapy for control of gastric variceal hemorrhage, and is probably equivalent to TIPS. In cases of endoscopic and/or pharmacological treatment failure with persistent uncontrollable bleeding, TIPS can be used as a rescue treatment by allowing a significant decrease or even normalization of the portal pressure and has demonstrated good results for bleeding control. ${ }^{24,25}$

Mishra SR et al found cumulative two-year survival rate of $90 \%$ with cyanoacrylate and $52 \%$ in $\beta$-blocker in patients while conducting randomized controlled trials and concluded that lower survival rate in those using beta blockers was due to rebleeding in those. There is no Procedure related complication found in Seewald et $\mathrm{a}^{26}$ and our study, however certain complications like vomiting and nausea can happen with usage of Cyanoacrylate injection. Cheng et al have reported few side effects after endoscopic cyanoacrylate injection. ${ }^{27}$ Glue injection is very rarely associated with serious complications though major one is systemic embolization. ${ }^{28}$ Infarction in multiple organs, cerebral stroke, chances of embolic settlement in pulmonary arteries along with thrombosis in various venous channels can happen as embolic events. ${ }^{29}$

\section{CONCLUSION}

$\mathrm{N}$-butyl-2-cyanoacrylate injection is very effective and safe in treating gastric variceal bleeding which is achieved in most of the cases in our study amid standardization in injecting technique and experienced hands.

\section{Copyright $@$}

\section{REFERENCES}

1. Sarin SK, Mishra SR. Endoscopic therapy for gastric varices. Clin Liver Dis. 2010 May; 14(2):263-79.

2. Saad WE, Darcy MD. Transjugular Intrahepatic Portosystemic Shunt (TIPS) versus Balloon-occluded Retrograde Transvenous Obliteration (BRTO) for the management of gastric varices. Seminlntervent Radiol. 2011 Sep; 28(3):339-49.

3. Soehendra N, Grimm H, Nam VC, Berger B. N-butyl2-cyanoacrylate: $A$ supplement to endoscopic sclerotherapy. Endoscopy. 1987; 19:221-4.

4. Sarin SK, Lahoti D, Saxena SP, Murthy NS, Makwana UK. Prevalence, classification and natural history of gastric varices: A long-term follow-up study in $\mathbf{5 6 8}$ portal hypertension patients. Hepatol. 1992; 16:13439.

5. Young-Suk L. Practical approach to endoscopic management for bleeding gastric varices. Korean $\mathrm{J}$ Radiol. 2012 Jan-Feb; 13(1):S40-S44.

6. Christodoulou D, Tsianos EV, Kortan P, Marcon N. Gastric and ectopic varices - newer endoscopic options. Ann Gastroenterol. 2007; 20(2):95-109.

7. Feretis C, Tabakopoulos D, Benakis P, Xenofontos M, Golematis B. Endoscopic hemostasis of esophageal and gastric variceal bleeding with histoacryl. Endoscopy. 1990; 22:282-4.

8. Serin SK, Lahoti D, Saxena SP, et al. Prevalence, Classification and natural history ogastric varices; a long term follow-up study in $\mathbf{5 6 8}$ portal hypertension patients. Hepatology 1992; 16: 1343 - 49.

9. Garcia-Tsao G, Sanyal AJ, Grace ND, Carey W. Practice guidelines committee of the American association for the study of liver diseases, practice parameters committee of the American college of gastroenterology. Prevention and management of gastroesophageal varices and variceal hemorrhage in cirrhosis. Hepatology. 2007; 46:922-38. [PubMed: 17879356].

10. Soehendra N, Nam VC, Grimm H, Kempeneers I. Endoscopic obliteration of large esophagogastric varices with bucrylate. Endoscopy. 1986; 18:25-6. 
11. Lo $\mathrm{GH}$, Lai $\mathrm{KH}$, Chen JS, et al. A prospective, randomized trial of butyl cyanoacrylate injection versus band ligation in the management of bleeding gastric varices. Hepatology 2001; 33: 1060 - 64 . 6. Sarin SK. Long-term follow-up of gastric variceal sclerotherapy: An eleven years' experience. Gastrointest Endosc 1997; 46: 8-14.

12. De Franchis R, Baveno V Faculty. Revising consensus in portal hypertension: Report of the Baveno $V$ consensus workshop on methodology of diagnosis and therapy in portal hypertension. J Hepatol. 2010; 53:762-8.

13. Mosli MH, Aljudaibi B, Almadi M, Marotta P. The safety and efficacy of gastric fundal variceal obliteration using N-butyl-2-cyanoacrylate; The experience of a single Canadian tertiary care centre. Saudi J Gastroenterol. 2013 10.4103/1319-3767.114508.

14. Hadayat R, Jehangiri AR, Gul R. Endoscopic findings of upper gastrointestinal bleeding in patients with liver cirrhosis. J Ayub Med Coll Abbottabad. 2015; 27(2):391-4.

15. Hameed K, Khan Y, Saeed A, Ahmad I, Javed M, Rehman S, et al. Injection sclertherapy of bleeding gastric varices using absolute alcohol. J Pak Med Inst. 2010; 24(02):111-4.

16. Samiullah S, Memon MS, Memon HG, Ghori A. Secondary gastric varices in hepatic cirrhosis. J Coll Physicians Surg Pak. 2011 Oct; 21(10):593-6.

17. Khan A, Manan F, Rahmanud Din. Outcome of endoscopic band ligation. Gomal J Med Sci. Jan-Jun 2013; 11:1.

18. Chang CJ, Hou MC, Liao WC, Lee FY, Lin HC, Lee SD. Risk factors of early re-bleeding and mortality in patients with ruptured gastric varices and concomitant hepatocellular carcinoma. J Gastroenterol. 2012; 47:531-9.

19. Al-Hillawi L, Wong T, Tritto G, and Berry PA. Pitfalls in histoacryl glue injection therapy for oesophageal, gastric and ectopic varices: A review. World J Gastrointest Surg. 2016 Nov 27; 8(11): 729-734.

20. Ríos Castellanos, E.; Seron, P.; Gisbert, J.P.; Cosp, $X . B$. Endoscopic injection of cyanoacrylate glue versus other endoscopic procedures for acute bleeding gastric varices in people with portal hypertension. Cochrane Database Syst. Rev. 2015, CD010180.
21. Onofrio, F.Q.; Pereira-Lima, J.C.; Valença, F.M.; Azeredo-da-Silva, A.L.F.; Tetelbom Stein, A. Efficacy of endoscopic treatments for acute esophageal variceal bleeding in cirrhotic patients: Systematic review and meta-analysis. Endosc. Int. Open 2019, 7, E1503-E1514.

22. Oh SH, Kim SJ, Rhee KW, Kim KM. Endoscopic cyanoacrylate injection for the treatment of gastric varices in children. World J Gastroenterol. 2015; 21:2719-2724. doi: 10.3748/wjg.v21.i9.2719.

23. Al-Hillawi L, Wong T, Tritto G, Berry PA. Pitfalls in histoacryl glue injection therapy for esophageal, gastric and ectopic varices: A review. World J Gastrointest Surg. 2016; 8(11):729. doi:10.4240/wjgs. v8.i11.729.

24. Garcia-Tsao, G.; Abraldes, J.G.; Berzigotti, A.; Bosch, J. Portal hypertensive bleeding in cirrhosis: Risk stratification, diagnosis, and management: 2016 Practice Guidance by the American Association for the Study of Liver Diseases. Hepatology 2017, 65, 310-335.

25. Loffroy, R. Transjugular Intrahepatic Portosystemic Shunt (TIPS): A major step forward for patients but a growing job for interventional radiologists! Diagn. Interv. Imaging 2016, 97, 1069-1070.

26. Tan $\mathrm{PC}, \mathrm{Hou} \mathrm{MC}$, Lin $\mathrm{HC}$, et al. A randomized trial of endoscopic treatment of acute gastric variceal haemorrhage: $\mathrm{N}$-butyl-2- cyanoacrylate injection versus band ligation. Hepatology 2006; 43: 690 m- 97.

27. Seewald S, Ang TL, Imazu H, Naga M, Omar S, Groth $S$, et al. A standardized injection technique and regimen ensures success and safety of N-butyl-2cyanoacrylate injection for the treatment of gastric fundal varices. Gastrointest Endosc.2008 Sep; 68(3):447-54.

28. Cheng LF, Wang ZQ, Li CZ, Lin W, Yeo AE, Jin B. Low incidence of complications from endoscopic gastric variceal obturation with butyl cyanoacrylate. ClinGastroenterol Hepatol. 2010 Sep; 8(9):760-6. Kobilica N, Flis V, Sojar V Major Complication after Histoacryl injection Endoscopy 2012; 44: E204-E205.

29. Watanabe K, Kimura K, Matsutani S, et al. Portal hemodynamics in patients with gastric varices. A study in 230 patients with esophageal and/or gastric varices using portal vein catheterization. Gastroenterology 1988; 95:434-40. 


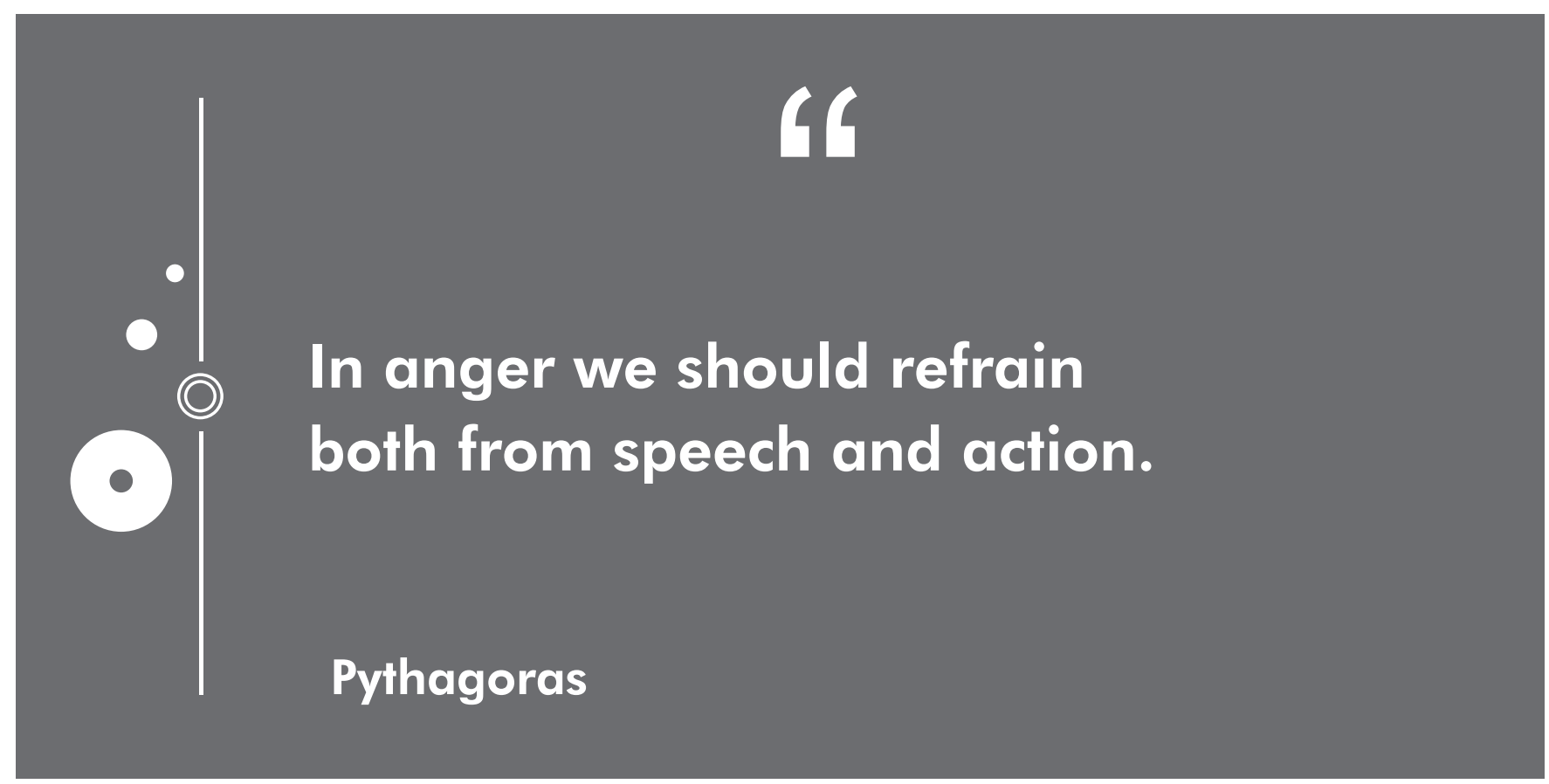

\begin{tabular}{|c||c|c|c|}
\hline \multicolumn{2}{|c|}{ AUTHORSHIP AND CONTRIBUTION DECLARATION } \\
\hline Sr. \# & Author(s) Full Name & \multicolumn{1}{c|}{ Contribution to the paper } & Author(s) Signature \\
\hline 1 & Ameet Jesrani & $\begin{array}{l}\text { Contribution to covergtion } \\
\text { of design acquisition of } \\
\text { data. } \\
\text { Drafting of of the article and } \\
\text { review it, expert research } \\
\text { opinion and experiense } \\
\text { from in the manage. } \\
\text { Contribution and congenital } \\
\text { and initilization oof data and } \\
\text { his expertise. } \\
\text { Contribution and congenital } \\
\text { and initilization oof data and } \\
\text { his expertise. }\end{array}$ \\
\hline Seema Nayab & Riaz Hussain Awan & Latif Aziz Memon & \\
\hline
\end{tabular}

